\title{
Additive Manufacturing of High-Entropy Alloys by Laser Processing
}

\author{
V. OCELÍK, ${ }^{1,2}$ N. JANSSEN, ${ }^{1}$ S.N. SMITH, ${ }^{1}$ and J.TH.M. DE HOSSON ${ }^{1}$ \\ 1.-Department of Applied Physics, Zernike Institute for Advanced Materials, University of \\ Groningen, 9474 AG Groningen, The Netherlands. 2.—e-mail: v.ocelik@rug.nl
}

This contribution concentrates on the possibilities of additive manufacturing of high-entropy clad layers by laser processing. In particular, the effects of the laser surface processing parameters on the microstructure and hardness of high-entropy alloys (HEAs) were examined. $\mathrm{AlCoCrFeNi}$ alloys with different amounts of aluminum prepared by arc melting were investigated and compared with the laser beam remelted HEAs with the same composition. Attempts to form HEAs coatings with a direct laser deposition from the mixture of elemental powders were made for $\mathrm{AlCoCrFeNi}$ and $\mathrm{AlCrFeNiTa}$ composition. A strong influence of solidification rate on the amounts of face-centered cubic and bodycentered cubic phase, their chemical composition, and spatial distribution was detected for two-phase $\mathrm{AlCoCrFeNi}$ HEAs. It is concluded that a high-power laser is a versatile tool to synthesize interesting HEAs with additive manufacturing processing. Critical issues are related to the rate of (re)solidification, the dilution with the substrate, powder efficiency during cladding, and differences in melting points of clad powders making additive manufacturing processing from a simple mixture of elemental powders a challenging approach.

\section{INTRODUCTION}

Alloying is accepted as a classic method to improve mechanical properties and performance, as for instance has been well executed in steel, aluminum, or magnesium alloys. In the field of "materials design," Yeh et al., ${ }^{1,2}$ made a breakthrough by putting forward the concept of "high-entropy alloys" (HEAs). These alloys are claimed to belong to a new class of materials that present novel phase structures and properties. In the literature, HEAs are defined to have at least five metal constituents in equimolar or near-equimolar ratios. ${ }^{2}$ Although HEAs with a hexagonal crystal structure have been reported ${ }^{3}$ previous studies have shown that most HEAs consist of simple face-centered cubic (fcc) or body-centered cubic (bcc) solid solutions instead of intermetallic or other complex phases due to the high-entropy effect. ${ }^{1}$ The underlying mechanism behind the HEAs is a minimization of the Gibbs free energy through a balance between entropy and enthalpy. ${ }^{4}$ The basic idea in developing HEAs is that a negative Gibbs free energy of mixing can be achieved, even when the enthalpy of mixing is positive or close to zero, through an increasing mixing entropy contribution with increasing temperature. Ideally this is so in the case of random solid solution (the so-called regular solution in the quasi-chemical approximation). This trick is often spoiled and hampered by the appearance of intermetallic compounds, and the basic idea should be considered as an interesting materials design guideline, not as a "necessary" and neither as a "sufficient" condition in materials design.

Nonetheless, a lot of research work has shown that HEAs possess many promising properties, such as high hardness, strength and ductility, ${ }^{5}$ superior thermal stability, excellent high-temperature oxidation resistance, high wear ${ }^{6-9}$ and corrosion resistance, ${ }^{10}$ and interesting magnetic properties. ${ }^{11}$ Apart from bulk material consolidation methods such as casting and sintering, HEAs can also be deposited as a surface coating. Various techniques of welding,,12 thermal spraying ${ }^{13}$ selective laser melting ${ }^{14}$ direct laser deposition ${ }^{8,15-18}$ and additive manufacturing $^{19-22}$ are already reported in the literature as experimental methods to produce HEA coatings.

Laser processing is particularly advantageous in synthesizing HEA coatings due to its ability to reach a high instantaneous temperature that leads to 
stabilizing the HEA phase due to high quench rates associated with the technique. ${ }^{16}$ In particular, rapid quenching becomes important as HEA may undergo various phase transformations while slowly cooling due to reduction in the thermodynamic driving force at lower temperatures. Furthermore, rapid quenching restricts diffusion of the elements and restricts nucleation and growth of the brittle intermetallic compounds, thereby retaining the HEA phase. ${ }^{16}$ Another advantage of direct laser deposition is that coatings could be deposited in a few steps, which eliminates the influence of the substrate and allows gradual chemical compositional changes through the coating thickness. ${ }^{23}$ Special additive manufacturing techniques like selective laser melting ${ }^{14}$ allow also for building three-dimensional (3D) dimensional objects directly from $\mathrm{FeCoCrNi} \mathrm{HEA}$ pre-alloyed powder, exhibiting high strength and ductility that are comparable with engineering materials like stainless steels. Direct deposition techniques like laser or TIG cladding are suitable to deposit HEA from a mixture of elemental powders. Such a mixture has been used to clad TiVCrAlSi HEA on Ti-6Al-4V substrate. ${ }^{15}$ We have noticed also disadvantages of these direct deposition methods of HEAs, namely, the evaporation of certain elements, different rates of intake of the powders, as well as dilution of the coating materials by the substrate during laser cladding. To avoid complications with powder feeding, a mixture of commercial pure elemental powders could be preplaced on the surface and then remelted by the laser beam. ${ }^{16,17,24}$

Typically, a slow laser beam scanning speed $(<10 \mathrm{~mm} / \mathrm{s})$ is used to allow a proper mixture of elemental phases inside the melt pool formed under the laser beam. ${ }^{17,25-27}$ However, these scanning speeds still result in much higher solidification rates than during classic arc melting and casting. In the case when pre-alloyed HEA powders are used, ${ }^{22}$ a wider range of scanning speeds could be used to study the influence of solidification rates on the microstructure and properties of laser-deposited HEAs. It is expected that a decrease of grain size of $\mathrm{AlCoCrFeNi}$ deposits with increasing scanning speed will increase the microhardness.

The microstructure, phases, and properties of the HEA system $\mathrm{Al}_{x} \mathrm{CoCrFeNi}(x=0-1.8)$ were recently studied by Wang et al. ${ }^{28}$ at room and elevated temperatures. A rather strong influence of $\mathrm{Al}$ on the phases at room temperature as well as at elevated temperatures was investigated. At a low $\mathrm{Al}$ content $(x=0-0.3)$, an fcc solid solution phase is formed, followed by a mixture of fcc and bcc phases for higher amounts of $\mathrm{Al}$ and a pure bcc for $\mathrm{Al}$ content higher than $x=1.2$. The microstructure is also influenced by homogenization at elevated temperatures, which usually follows the casting.

Comparative study of arc melted and laser beam fabricated $\mathrm{Al}_{x} \mathrm{CoCrFeNi}(x=0.3,0.6$, and 0.85$)$ $\mathrm{HEAs}^{19}$ shows similar microstructures for low and high $\mathrm{Al}$ content alloys with a strong $\langle 001\rangle$ fiber texture along the direction of solidification. A very first review of HEA coatings fabricated mainly by laser cladding and their application prospects was published by Zhang et al. ${ }^{29}$

The goal of our experimental work is a comparative study of the microstructure and hardness among HEAs prepared by conventional arc melting with a laser-beam-assisted surface coating technique. Laser beam remelting of $\mathrm{Al}_{x} \mathrm{CoCrFeNi} \mathrm{HEAs}$ should demonstrate the strong influence of the (re)solidification rate on the microstructure and properties of HEAs, i.e., different for conventional casting and laser surface treatments. Direct laser deposition of HEA coatings from elemental powders mixture should prove an ability of this method for fast and versatile HEA surface coatings fabrication.

\section{EXPERIMENTAL PROCEDURE}

The HEAs studied in this work were prepared by vacuum arc melting and by laser processing. Ingots with nominal compositions of $\mathrm{Al}_{x} \mathrm{CoCrFeNi}$ ( $x$ values in molar ratios, $x=0.3,0.5$, and 0.7 ) alloys were prepared by arc-melting, homogenized at $1250^{\circ} \mathrm{C}$, and forged at the same temperature with reduction of 50\%. Energy dispersive x-ray spectroscopy (EDS) analysis performed after sample preparation reveals different compositions in comparison with the nominal compositions. In the following, the specimens will be marked according their real chemical compositions: $0.4,0.7$, and 1.0 , respectively.

The second set of specimens was prepared by surface laser remelting of the samples prepared as mentioned earlier. The surface was sandblasted to increase absorption of the laser beam and then remolten using the $1.07-\mu \mathrm{m}$ wavelength radiation generated by $3-\mathrm{kW}$ IPG Fiber laser. A laser beam spot with a diameter of $1.5 \mathrm{~mm}$ (Gaussian distribution) was used to scan the surface with speeds of 5 and $10 \mathrm{~mm} / \mathrm{s}$ and laser power of 300 and $450 \mathrm{~W}$, respectively.

A third group of samples was prepared by direct laser beam deposition on the SS 305 steel bar substrate using the laser beam scanning speed of $5 \mathrm{~mm} / \mathrm{s}$ and laser power between 600 and $650 \mathrm{~W}$. A premixture of pure elemental powders (particles size between $5 \mu \mathrm{m}$ and $120 \mu \mathrm{m}$ ) with equimolar nominal compositions of $\mathrm{AlCoCrFeNi}$ and $\mathrm{AlCrFe}-$ NiTa was fed by a Sulzer Metco Twin10C powder feeder using a side cladding nozzle and forming a single layer coating with a thickness of about 500$800 \mu \mathrm{m}$. To avoid modification of the chemical composition due to dilution from the molten steel, substrate multiple layer coatings were created so that the effects of dilutions at the outer layer are minimized.

Samples for microstructural investigations and hardness measurements were cut and prepared by standard mechanical grinding and lapping with suspensions containing $9-\mu \mathrm{m}, 3-\mu \mathrm{m}$, and $1-\mu \mathrm{m}$ diamond particles and polishing with oxide polishing 
suspension (OPS) colloidal silica. A Philips XL30 Field Emission Gun scanning electron microscope (SEM) and Tescan Lyra Dual beam system were used for microstructural observations in secondary electron (SE) and backscattered electron (BSE) imaging mode. The constituent phases were determined using a combination of EDS and electron backscatter diffraction (EBSD) using an EDAX Octane Super EDS detector and TSL EBSD system equipped with a Hikari Super CCD camera. Team 4.2 data collection and analysis software was used; EBSD data were further analyzed by TSL OIM Analysis 7.3 software.

The XRD analyses were done using an x-ray diffractometer (XRD, Bruker D8 Advance) with Cu $\mathrm{K} \alpha$ radiation. The samples were scanned over a $2 \theta$ range from $20^{\circ}$ to $120^{\circ}$ with a step size of $0.02^{\circ}$ and a step time of $10 \mathrm{~s}$. The XRD spectra were analyzed using Match software.

\section{RESULTS AND DISCUSSION}

\section{Arc-Melted $\mathrm{Al}_{x} \mathrm{CoCrFeNi}$ HEAs}

The peaks in the XRD spectra were assigned to the crystallographic planes and phases in the samples prepared by arc melting. The assignment agreed well with literature. ${ }^{28}$ Closer inspection of the position of (111) fcc phase peak revealed a peak shift with increasing aluminum concentration. This convolutes to a shift in the fcc lattice parameter from $a_{\mathrm{Al} \_0.4}=3.560 \AA$ to $a_{\mathrm{Al} \_0.7}=3.592 \AA$ and to $a_{\mathrm{Al} \_1.0}=\overline{3} .603 \AA$. This phenomenon is expected since aluminum atoms are much larger than the other constituent atoms. A similar feature is observed for the bcc lattice parameter as Table I clearly demonstrates. The lattice parameters of both phases were calculated by averaging the lattice parameters derived from the various peaks in the XRD spectra.

The reason why the peak shift is significantly larger from $\mathrm{Al} \_0.4$ to $\mathrm{Al} \_0.7$ than for Al_0.7 to $\mathrm{Al} \_1.0$ was explained by Wang et al. ${ }^{28}$ to be an upper limit of aluminum concentration in the fcc and bcc phases. At that limit, the chemical compositions of the two phases does not change anymore; i.e., only the relative amount of fcc with respect to bcc changes.

As Fig. 1 clearly demonstrates, there are different amounts of fcc and bcc phase present in arc-melted samples. Al_0.4 contains 99.9\%, Al_0.7 contains
97.0\%, and Al_1.0 contains $65.3 \%$ of fcc phase, respectively. Figure 2 summarizes the microstructural study of the $\mathrm{Al} \_1.0$ sample by a combination of EDS and EBSD mapping technique from a larger area $\left(250 \times 550 \mu \mathrm{m}^{2}\right.$ with step of $\left.0.4 \mu \mathrm{m}\right)$. The [001] inverse pole figure map (Fig. 2a) shows no preferential grains orientation for neither the bcc nor the fcc phase. However, different deformation mechanisms could be clearly detected in the fcc and bcc phases. The fcc phase is full of $\Sigma 3$ twins $\left(60^{\circ} @\langle 111\rangle\right)$, shown as yellow lines in all maps depicted in Fig. 2. Figure 2c shows the ratio between parent and daughter fraction of fcc grains. A total of $88.5 \%$ of fcc grains are twinned with $35 \%$ of twinned volume. On the other side, the bcc phase is characterized by large, highly deformed grains. Figure $2 d$ shows the map of local average misorientation, indicating a high local deformation through dislocation glide and climb mechanisms. High plastic deformation found in all three arc-melted samples is a consequence of the $50 \%$ forging applied in the last step of their preparation.

The EDS maps in Fig. 2 show clearly elemental segregation. The bcc phase is rich of aluminum and nickel, whereas the fcc phase is rich of chromium and iron. Table II summarizes elemental compositions of both phases in all three samples measured by EDS. The relative amounts of $\mathrm{Co}, \mathrm{Cr}, \mathrm{Fe}$, and $\mathrm{Ni}$ are almost the same for all three alloys. The composition of the fcc phase in Al_0.7 and Al_1.0 is also very close to each other, but the composition of the bcc phase in these two is different. The bcc phase in Al_1.0 is less rich of $\mathrm{Al}$ and $\mathrm{Ni}$, and more rich of $\mathrm{Co}, \overline{\mathrm{Cr}}$, and $\mathrm{Fe}$.

The grain size distributions of arc-melted samples are plotted in Fig. 3. The grain sizes of the different samples vary greatly. In $\mathrm{Al}_{0.4} \mathrm{CoCrFeNi}$, the grain size is larger than $500 \mu \mathrm{m}$ in diameter. $\mathrm{In} \mathrm{Al}_{0.7} \mathrm{CoCr}-$ $\mathrm{FeNi}$, small equiaxed grains of bcc appear surrounded by much bigger equiaxed fcc grains, although in this particular alloy, the fcc grains are much smaller than in $\mathrm{Al}$ 0.4. With $\mathrm{AlCoCrFeNi}$, the fraction of bcc is even higher. The bcc grains are bigger and the fcc grains smaller than in Al_0.7. The bcc grains form large connected grains in between the fcc phase.

Vickers hardness tests showed differences in hardness between the samples, The hardness is almost doubled going from Al_0.4 (148 HV) to Al_1.0 $(278 \mathrm{HV})$. This increase in hardness is attributed to

Table I. Lattice parameters $(\AA)$ for the fcc and bcc phase in arc-melted $\mathrm{Al}_{x} \mathrm{CoCrFeNi}$ samples calculated from corresponding peak positions in XRD spectra with their standard deviations

\begin{tabular}{|c|c|c|c|c|c|c|}
\hline & $\underline{a_{\mathrm{Al} \_0.4}}$ & std & $\underline{a_{\text {Al_0.7 }}}$ & std & $\underline{a_{\text {Al_1.0 }}}$ & std \\
\hline fcc & 3.581 & 0.030 & 3.596 & 0.003 & 3.605 & 0.003 \\
\hline bcc & 2.880 & 0.004 & 2.899 & 0.010 & 2.890 & 0.011 \\
\hline
\end{tabular}

std standard deviation. 

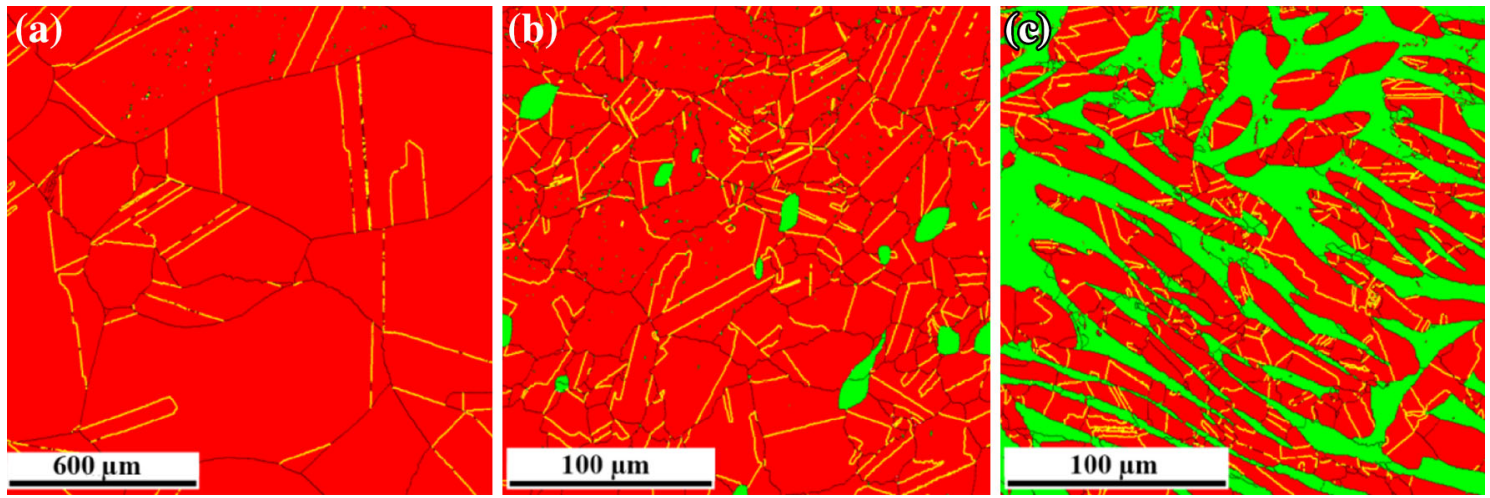

Fig. 1. EBSD phase map of (a) Al_0.4, (b) Al_0.7, and (c) Al_1.0 arc-melted samples showing fcc (red) and bcc (green) phases. Grain boundaries $\left(>5^{\circ}\right.$, black lines) and $\Sigma 3$ twin boundaries (yellow lines) in fcc phase are also shown.

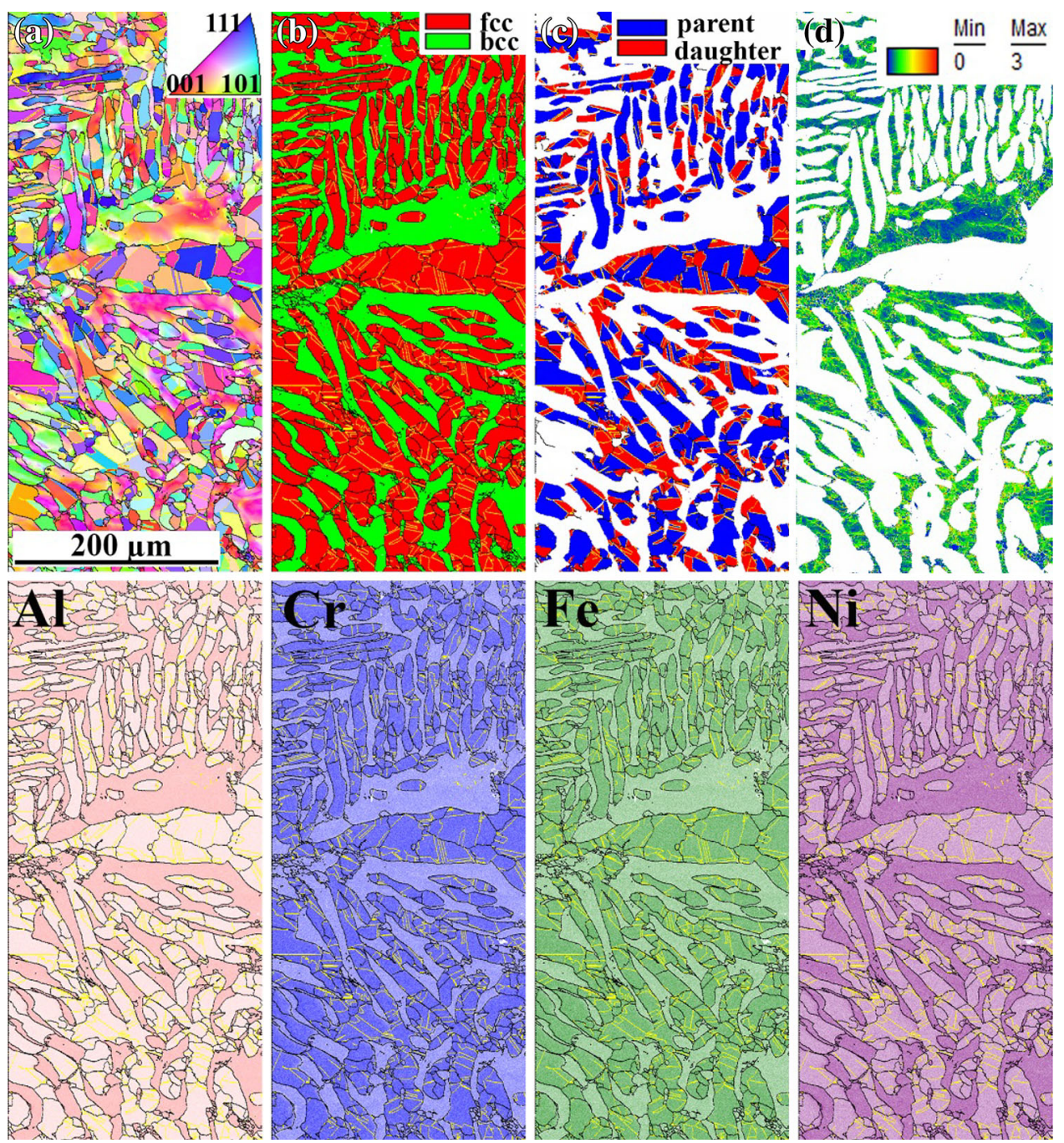

Fig. 2. Microstructural characteristics of Al_1.0 alloy studied by combination of EBSD and EDS mapping of about $1 \mathrm{M}$ points with step of $0.4 \mu \mathrm{m}$. (a) [001] Inverse pole figure with $5^{\circ}$ grain boundaries (black lines) and $\Sigma 3$ twin boundaries (yellow lines) in fcc phase; (b) EBSD phase map; (c) EBSD map of parent and daughter $\Sigma 3$ twins in fcc phase; (d) local average misorientation map in bcc phase (blue $0^{\circ}$, red $3^{\circ}$ ). Bottom: Al, Cr, Fe, and $\mathrm{Ni}$ concentration EDS maps showing Al, Ni-rich bcc, and Cr-, Fe-rich fcc phases. Grain boundaries ( $>5^{\circ}$ in black) and $\Sigma 3$ twins in fcc phase (yellow) are also shown. 
Table II. Overall chemical composition (at.\%) of the arc-melted samples and compositions of the phases therein determined by EDS analysis (note that the Al_0.4 consists of the fcc phase only)

\begin{tabular}{|c|c|c|c|c|c|c|c|}
\hline & \multirow{2}{*}{$\underset{\text { fec }}{\text { Al_0.4 }}$} & \multicolumn{3}{|c|}{ Al_0.7 } & \multicolumn{3}{|c|}{ Al_1.0 } \\
\hline & & Overall & fec & bcc & Overall & fec & bce \\
\hline $\mathrm{Al}$ & 9.3 & 14.6 & 13.7 & 33.0 & 19.8 & 13.3 & 27.2 \\
\hline $\mathrm{Co}$ & 22.9 & 21.6 & 21.9 & 16.5 & 20.5 & 22.2 & 18.5 \\
\hline $\mathrm{Cr}$ & 22.7 & 21.5 & 21.8 & 11.2 & 20.0 & 23.2 & 16.1 \\
\hline $\mathrm{Fe}$ & 22.7 & 21.4 & 21.9 & 12.7 & 20.0 & 23.1 & 16.2 \\
\hline $\mathrm{Ni}$ & 22.4 & 20.9 & 20.7 & 26.6 & 19.7 & 18.2 & 22.0 \\
\hline
\end{tabular}

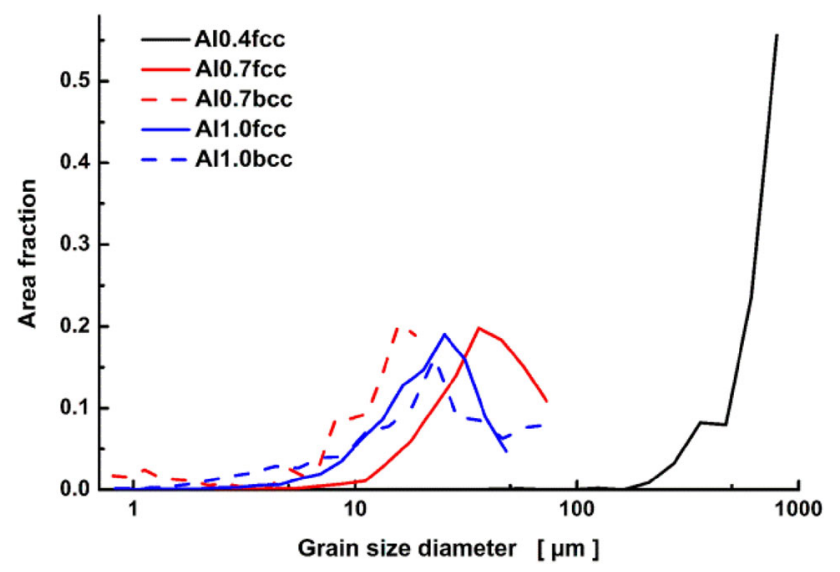

Fig. 3. Grain size distributions of the fcc and bcc phases of the arcmelted samples; twin boundaries and grains at the edge of the scans are excluded.

the increase of the fraction of bcc phase in the alloy. The Al_0.4 has almost no bcc phase. The phase fraction of bcc in $\mathrm{Al} 0.7$ is only $3 \%$, and a small increase of $40 \mathrm{HV}$ is measured with respect to Al_0.4. However, the hardness increases of $90 \mathrm{HV}$ going from Al_0.7 to $\mathrm{Al}$ 1.0, where the phase fraction of bcc is approximately $35 \%$. The increase of the interface area between fcc and bcc phases and the reduction of grain size probably also contributes by reducing the mean free path length of moving dislocations.

\section{Laser Beam Remelted $\mathrm{Al}_{x} \mathrm{CoCrFeNi}$ HEAs}

To investigate the microstructure and properties of HEAs with the same compositions, but faster solidification, remelted tracks were made on the original arc-melted samples using a moving laser beam. Two tracks were remelted in each of the three samples. One track had a laser power of $300 \mathrm{~W}$ with a beam speed of $5 \mathrm{~mm} / \mathrm{s}$ and one track had a laser power of $450 \mathrm{~W}$ at a beam speed of $10 \mathrm{~mm} / \mathrm{s}$, hereinafter referred to as Track1 and Track2, respectively. Both tracks were approximately $1.2 \mathrm{~mm}$ wide.
The remelted tracks in $\mathrm{Al}_{0.4} \mathrm{CoCrFeNi}$ do not show any change with respect to the nonremelted alloy. The phase and orientations of the grains inside the remelted area are not modified. Since the grain size was bigger than the depth of the remelted track, this suggests that during the resolidification inside the molten zone, the grains keep the orientation of the grains that were there originally. This was the case for both remelting speeds. The overall compositions of the remelted zones in the rest of the samples shown in Table III resemble the compositions of the nonremelted samples quite well. This can be seen by comparing Table II with Table III.

The phases observed in the remelted samples are also the same as the phases seen in the original arcmelted samples and so are the phase fractions outside the remelted zones. However, the phase fractions and distribution of fcc and bcc phases inside the remelted zones differ substantially, as well as the elemental compositions of fcc and bcc phases. In the microstructure of a remelted Al_0.7 sample, there are some remarkable microstructural changes, as depicted in Fig. 4. The grain size of the fcc phase in the remelted zone is reduced to about $30 \mu \mathrm{m}$ in diameter, and only very small islands of the bcc phase could be detected on an overall scan shown in Fig. 4a. The detailed scan inside the remelted zone (Fig. 4b) reveals a dendritic structure of fcc grains and the presence of bcc phase only inside interdendritic areas with the size of individual islands of about $2 \mu \mathrm{m}$ in diameter. However, crystallographic orientation of these islands is the same inside one fcc dentritic grain, which means that the bcc phase solidified at the end of solidification as an "eutectic phase." The amount of the bcc phase in the remelted zone has increased to $7.5 \%$ in comparison with only $3 \%$ in the nonremelted Al_0.7 sample. EDS maps for this detailed scan are shown at the bottom of Fig. 4. They clearly discover elemental partitioning for $\mathrm{Al}$ and $\mathrm{Fe}$, while the other three elements were partitioned much less, as Table III also demonstrates.

The mechanism that favors the formation of the bcc phase in rapidly solidified volumes becomes apparent in remelting of the Al_1.0 sample (see 
Table III. Overall composition (at.\%) of the remelted tracks and compositions of their phases determined by EDS analysis

\begin{tabular}{|c|c|c|c|c|c|c|c|c|}
\hline & \multicolumn{6}{|c|}{ Al_0.7 } & \multicolumn{2}{|c|}{ Al_1.0 } \\
\hline & \multicolumn{3}{|c|}{ Track1 } & \multicolumn{3}{|c|}{ Track2 } & \multirow{2}{*}{$\begin{array}{c}\text { Track1 } \\
\text { bce }\end{array}$} & \multirow{2}{*}{$\begin{array}{l}\text { Track2 } \\
\text { bec } \\
\end{array}$} \\
\hline & Overall & fec & bce & Overall & fec & bce & & \\
\hline $\mathrm{Al}$ & 14.9 & 13.4 & 19.7 & 15.3 & 14.2 & 19.6 & 19.9 & 20.1 \\
\hline Co & 21.5 & 22.3 & 19.1 & 21.4 & 22.1 & 19.2 & 20.4 & 20.5 \\
\hline $\mathrm{Cr}$ & 21.3 & 21.4 & 21.2 & 21.2 & 21.1 & 21.2 & 20.0 & 19.9 \\
\hline $\mathrm{Fe}$ & 21.4 & 22.5 & 18.4 & 21.3 & 22.1 & 18.7 & 20.1 & 20.0 \\
\hline $\mathrm{Ni}$ & 20.9 & 20.4 & 21.6 & 20.8 & 20.5 & 21.3 & 19.6 & 19.5 \\
\hline
\end{tabular}
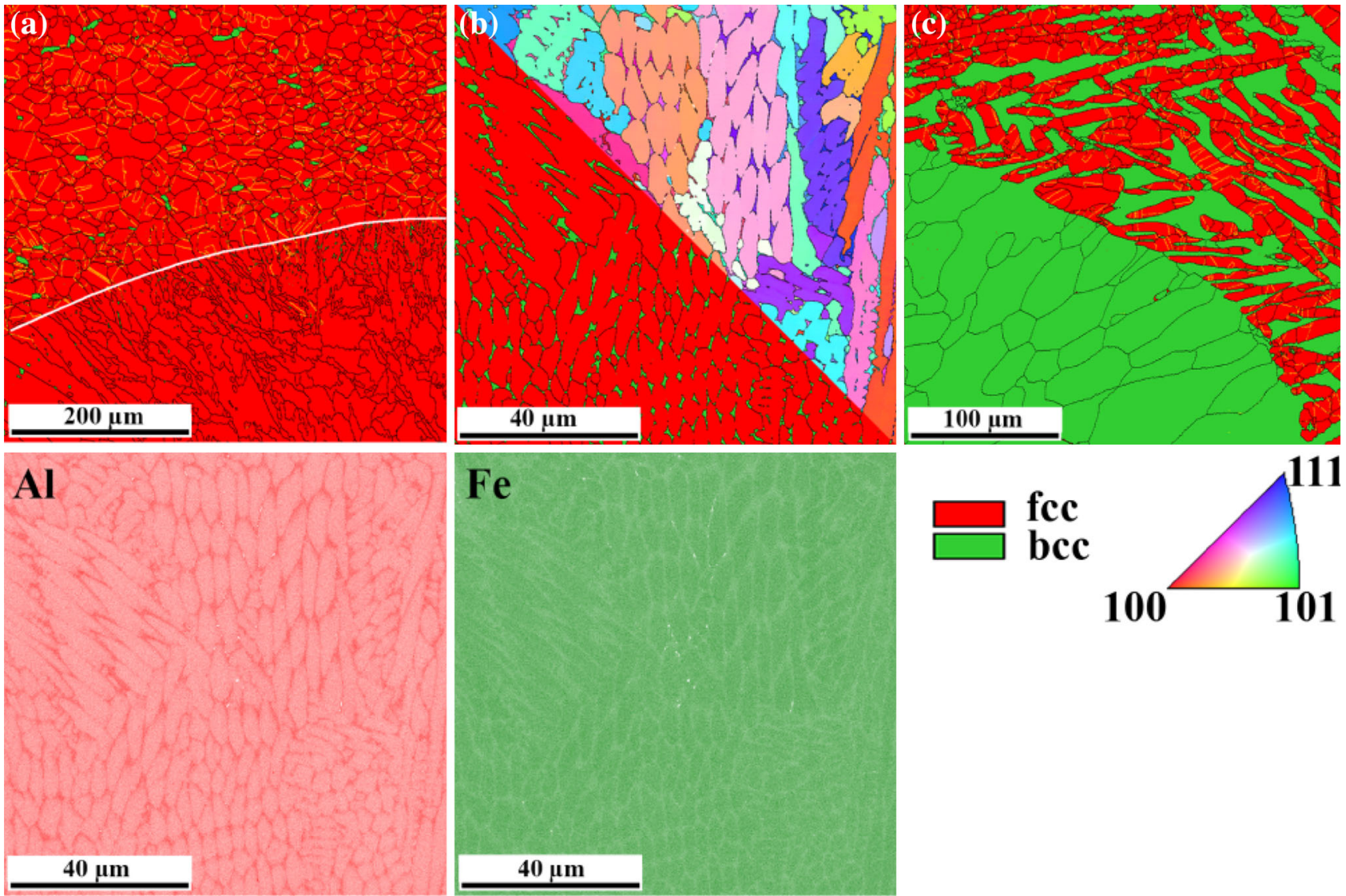

Fig. 4. Microstructural characteristics of AI_0.7 and AI_1.0 alloy after laser beam remelting studied by a combination of EBSD and EDS mapping. (a) EBSD phase map of the interface between substrate and remelted zone of Al_0.7 sample. Interface is marked by white line, and laser remelted zone at the bottom; (b) combination of [001] inverse pole figure map (top-right) and phase map (bottom-left) inside remelted zone of Al_0.7 sample; (c) EBSD phase map of the interface between substrate and remelted zone of Al_1.0 sample, and laser remelted zone at the bottom; bottom: Al and Fe concentration EDS maps inside of remelted zone shown in (b).

Fig. 4c). In this alloy the entire remelted zone has turned into big columnar bcc phase grains (up to $100 \mu \mathrm{m}$ long and tens of microns wide), elongated in the solidification direction. The phase fraction of bcc is $99.9 \%$. This difference with the phases present in the original vacuum arc-melted sample (bcc phase fraction of $35 \%$ ) finds its origin in the high solidification rate after laser remelting. We estimated cooling rates in our remelting experiments using a simple laser melting model, ${ }^{30}$ with $3.9 \times 10^{3} \mathrm{~K} / \mathrm{s}$ and $3.3 \times 10^{4} \mathrm{~K} / \mathrm{s}$, for a laser beam velocity of $5 \mathrm{~mm} / \mathrm{s}$ and $10 \mathrm{~mm} / \mathrm{s}$, respectively. It is clear that these cooling rates do not allow the full partitioning required for the formation of two 
phase in this HEA. When the overall composition becomes close to composition of the bcc phase, the fast solidification allows only the formation of this bcc phase.

In Table III, the compositions of the phases inside the remelted tracks are also shown. In both Al_0.7 and Al_1.0, no apparent difference was observed between the tracks with different speeds, neither in composition nor microstructure. This means that these combinations of laser power and scanning speed yield a similar solidification behavior. The fact that we do not observe any microstructural changes in the so-called "heat-affected zone" (area where the temperature during remelting was just below $T_{m}$ ) confirms the high thermal stability of both Al_0.7 and Al_1.0 alloys prepared by the arcmelting process.

Compared with arc-melted samples, the hardness of Al_0.7 has increased by almost 20\%. This is due to the increased surface area between grains and phases because of the finer dendritic microstructure and a small increase in the amount of the bcc phase. In the case of $\mathrm{Al} 1.0$, the laser remelted track is twice as hard ( $270 \mathrm{HV})$ as the non-remelted sample. This is due to the fact that the phase of the remelted zone is now solely bcc, which is the harder phase, compared with fcc. From here on, we may conclude that the synthesis procedure itself, affecting the fraction and spatial distribution of phases, is a very important parameter determining the hardness of AlCoCrFeNi HEAs.

\section{Laser-Deposited AlCoCrFeNi and AlCrFeNiTa HEAs}

A couple of attempts were made to laser clad equimolar $\mathrm{AlCoCrFeNi}$ and $\mathrm{AlCrFeNiTa}$ compositions using a standard side powder feeding setup. ${ }^{31}$ The clads were made with a scanning speed of $5 \mathrm{~mm} / \mathrm{s}$ on a stainless steel bar substrate with a $50 \mathrm{~mm}$ diameter. In all cases, a 50\% laser track overlap was used to create continuous coatings, and up to three layers of the coatings were built to eliminate compositional change by dilution ${ }^{32,33}$ from the substrate. Equimolar mixtures of elemental powders with purity higher than $99.9 \%$ were fed using argon as a carrier gas into the melt pool created by a defocused laser beam (diameter of Gaussian beam of about $2.3 \mathrm{~mm}$ ). The typical laser power to clad one layer of the coating with a thickness of about $0.7-0.8 \mathrm{~mm}$ was $\sim 600-650 \mathrm{~W}$. We experienced that getting to an equimolar composition inside the HEAs coatings was a challenge. Starting with an equiatomic powder mixture does not mean that one ends up with the required composition. There are a few factors affecting the powder feeding efficiency for different elemental powders. Due to the different shapes, sizes, and densities of the powder particles, the probability for these particles to join the melt pool is also different.
Obviously, also the various melting temperatures of the elements employed may influence the final solidification composition.

Therefore, a few iterations of elemental powders mixture are necessary to achieve the final clad layer composition being close to the required target. The composition profile by EDS of one of our best $\mathrm{AlCoCrFeNi}$ laser clad coatings is shown in Fig. 5. Here the coating profile is seen in a longitudinal cross-section parallel to the laser beam propagation direction. The whole coating contains three clad layers and is about $2.3 \mathrm{~mm}$ thick. A clear dilution effect could be observed in the first clad layer, where Fe content substantially increased in a vicinity of the substrate. Quite a homogeneous elemental distribution is present in the second and third clad layer, although the amount of nickel is far from the expected 20 at.\%. Figure 5 also shows the longitudinal IPF map of the same layers. The map clearly demonstrates the columnar grain growth of bcc phase in the $\langle 001\rangle$ direction perpendicularly to the solidification front. ${ }^{34}$ The second and third layer each contains $99.9 \%$ of the bcc phase, and the average hardness of this HEA coating was $492 \pm 12$ HV.

Another attempt was made to clad a modified HEA composition. In this composition, Co was substituted by tantalum. Ta is a refractory element with an extremely high melting (3290 K) point. This melting point is even higher than the boiling point of aluminum (2792 K). The addition of tantalum was argued so as to give the alloy enhanced strength and structural stability at elevated temperatures due to an intensified sluggish diffusion. The composition was cladded with a scanning speed of $5 \mathrm{~mm} / \mathrm{s}$. Using a laser power of $600 \mathrm{~W}$, a single and double layer coating were made, both with $50 \%$ overlap between adjacent tracks. The single layer clad showed about $70 \%$ dilution.

As a result, the single layer coating and the first layer of the double layer coating contain a very high amount of iron (up to 54 at.\%) originating from the substrate. Even the second layer has still a high concentration of iron ( $\sim 34$ at.\%). Another observation that stands out is the incredibly low $\mathrm{Al}$ concentration in the top layer $(7$ at.\%). This is probably due to the evaporation from the very hot melt. Based on the SEM images displayed in Fig. 6 in combination with EDS analysis, we conclude that the AlCrFeNiTa laser clad coating consists of multiple phases. Throughout the coating, sporadic bright white spots appear. These spots are almost pure (about 94 at.\%) tantalum particles supposedly not molten in the laser cladding (Fig. 6a and c). On the top side of the clad (Fig. 6d), an equiaxed dendritic structure appears, clearly showing a two phase microstructure. The Vickers hardness values for this laser clad AlCrFeNiTa in the top layer are three times higher $(860 \mathrm{HV})$ than in the AlCoCrFeNi arc-melted sample. 

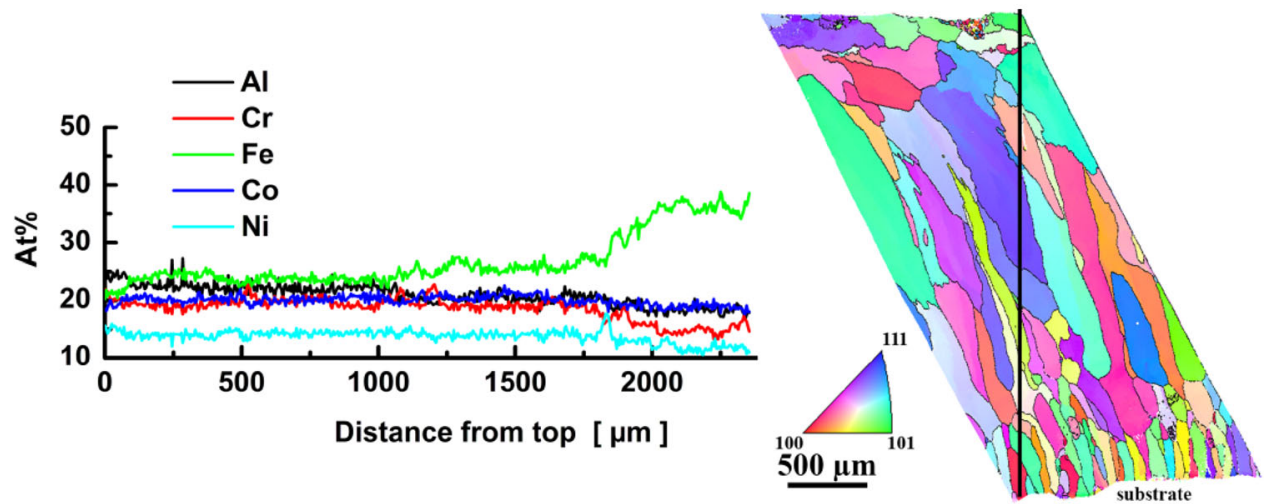

Fig. 5. EDS composition profile of three-layer AICoCrFeNi laser clad coating from the top (left) to the bottom along the black line shown in [001] IPF map on the longitudinal cross section of AICoCrFeNi laser clad coating.
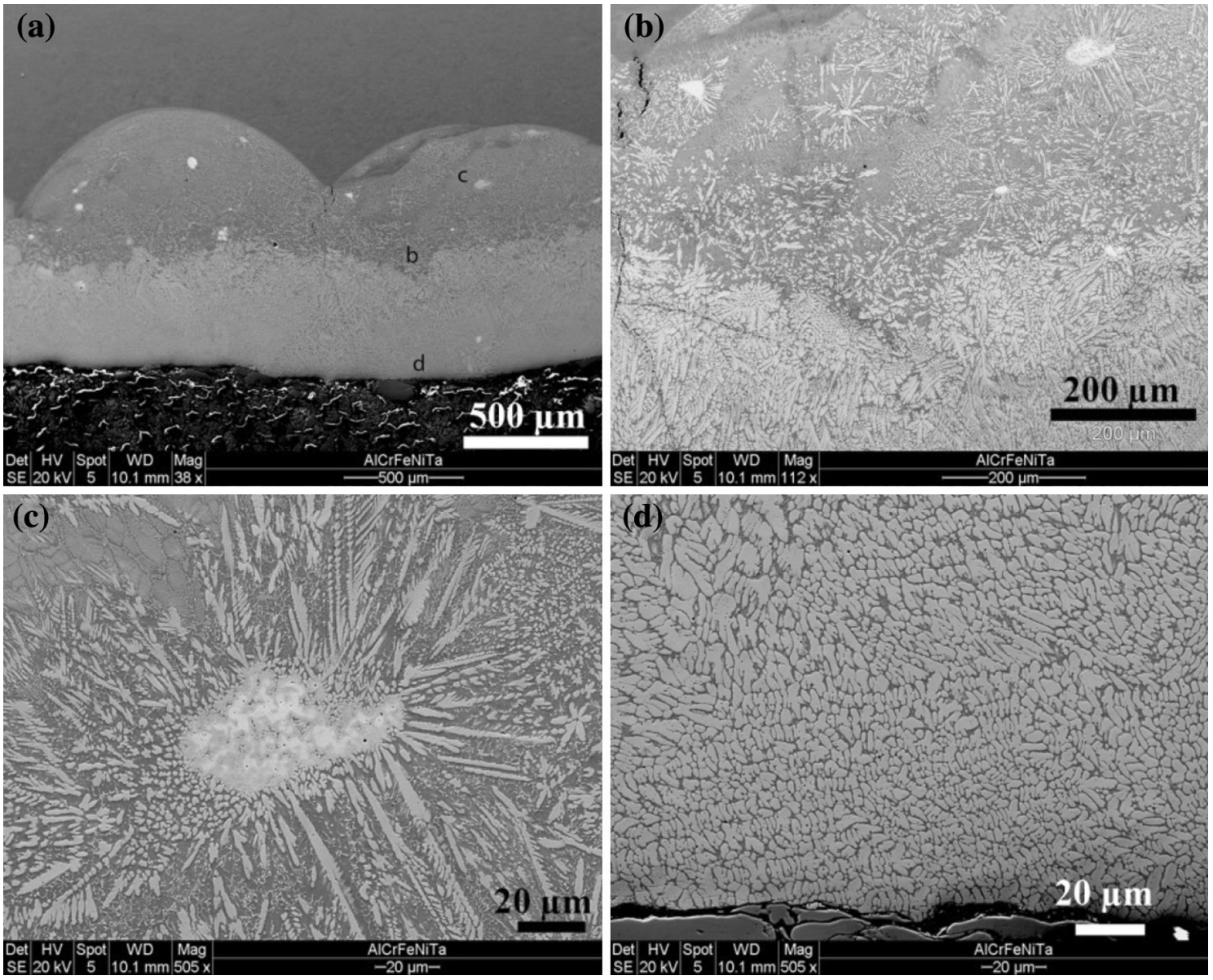

Fig. 6. Secondary electron SEM images from AICrFeNiTa laser clad coating. (a) An overview of the double-layered coating on transversal cross section. Note that the steel substrate is at the top. (b) Microstructure on the interface between layers. (c) Ta-rich area in the microstructure of the first layer. (d) Microstructure on the top of the second layer.

\section{CONCLUSION}

It is concluded that a high-power laser is a versatile tool to synthesize interesting high entropy alloys with additive manufacturing processing. From the laser remelting experiment, we see that the solidification rate is a very important factor for determination of the presence and distribution of phases in $\mathrm{AlCoCrFeNi}$ HEAs. Fast solidification substantially increases the preference for the bcc phase with a corresponding substantial increase in hardness. The high thermal stability of $\mathrm{AlCoCrFeNi}$ base HEA has been confirmed by the absence of a heat-affected zone in the vicinity of the remelting 
track. It goes without saying that the success of direct laser deposition of HEAs coatings using a feeding of mixture of elemental powders is affected by several materials and processing parameters, e.g., in-take of particular powders, melting temperatures, laser beam velocity, and power density.

\section{ACKNOWLEDGEMENTS}

Professor Peter K. Liaw and Dr. Z. Tang from the Department of Materials Science and Engineering, The University of Tennessee, are gratefully acknowledged for the preparation of arc-melted AlCoCrFeNi samples.

\section{OPEN ACCESS}

This article is distributed under the terms of the Creative Commons Attribution 4.0 International License (http://creativecommons.org/licenses/by/4.0/ ), which permits unrestricted use, distribution, and reproduction in any medium, provided you give appropriate credit to the original author(s) and the source, provide a link to the Creative Commons license, and indicate if changes were made.

\section{REFERENCES}

1. J.W. Yeh, S.K. Chen, S.J. Lin, J.Y. Gan, T.S. Chin, T.T. Shun, C.H. Tsau, and S.Y. Chang, Adv. Eng. Mater. 6, 299 (2004).

2. B.S. Murty, J.-W. Yeh, and S. Ranganathan, High Entropy Alloys (Burlington, MA: Butterworth-Heinemann, 2014).

3. M. Feuerbacher, M. Heidelmann, and C. Thomas, Mater. Res. Lett. 3, 1 (2015).

4. F. Otto, Y. Yang, H. Bei, and E.P. George, Acta Mater. 61, 2628 (2013).

5. K.B. Zhang, Z.Y. Fu, J.Y. Zhang, J. Shi, W.M. Wang, H. Wang, Y.C. Wang, and Q.J. Zhang, J. Alloy. Compd. 502, 295 (2010).

6. C.-J. Tong, M.-R. Chen, S.-K. Chen, J.-W. Yeh, T.-T. Shun, S.-J. Lin, and S.-Y. Chang, Metall. Mater. Trans. Phys. Metall. Mater. Sci. 36, 1263 (2005).

7. S. Varalakshmi, R. Appa, M. Kamaraj, and B.S. Murty, J. Mater. Sci. 45, 5158 (2010).

8. X. Ji, H. Duan, H. Zhang, and J. Ma, Tribol. Trans. 58, 1119 (2015).

9. Y.C. Lin and Y.H. Cho, Surf. Coat. Technol. 203, 1694 (2009).
10. Y.Y. Chen, T. Duval, U.D. Hung, J.W. Yeh, and H.C. Shih, Corros. Sci. 47, 2257 (2005).

11. Y. Zhang, T. Zuo, Y. Cheng, and P.K. Liaw, Sci. Rep. 3, 1455 (2013).

12. W. Huo, H. Shi, X. Ren, and J. Zhang, Adv. Mater. Sci. Eng. 2015, 1 (2015).

13. A.S.M. Ang, C.C. Berndt, M.L. Sesso, A. Anupam, P.S.R.S. Kottada, and B.S. Murty, Metall. Mater. Trans. A 46, 791 (2015).

14. Y. Brif, M. Thomas, and I. Todd, Scr. Mater. 99, 93 (2015).

15. C. Huang, Y. Zhang, J. Shen, and R. Vilar, Surf. Coat. Technol. 206, 1389 (2011).

16. S. Katakam, S.S. Joshi, S. Mridha, S. Mukherjee, and N.B. Dahotre, J. Appl. Phys. 116, 104906 (2014).

17. X.-W. Qiu and C.-G. Liu, J. Alloy. Compd. 553, 216 (2013).

18. X.-W. Qiu, Y.-P. Zhang, L. He, and C. Liu, J. Alloy. Compd. 549, 195 (2013).

19. J. Joseph, T. Jarvis, X. Wu, N. Stanford, P. Hodgson, and D.M. Fabijanic, Mater. Sci. Eng. A 633, 184 (2015).

20. I. Kunce, M. Polanski, and J. Bystrzycki, Int. J. Hydrogen Energy 38, 12180 (2013).

21. I. Kunce, M. Polanski, and J. Bystrzycki, Int. J. Hydrogen Energy 39, 9904 (2014).

22. I. Kunce, M. Polanski, K. Karczewski, T. Plocinski, and K.J. Kurzydlowski, J. Alloy. Compd. 648, 751 (2015).

23. B.A. Welk, R.E.A. Williams, G.B. Viswanathan, M.A. Gibson, P.K. Liaw, and H.L. Fraser, Ultramicroscopy 134, 193 (2013).

24. H. Zhang, Y. Pan, and Y.-Z. He, Mater. Des. 32, 1910 (2011).

25. H. Zhang, Y. Pan, Y. He, and H. Jiao, Appl. Surf. Sci. 257, 2259 (2011).

26. W. Wu, L. Jiang, H. Jiang, X. Pan, Z. Cao, D. Deng, T. Wang, and T. Li, J. Therm. Spray Technol. 24, 1333 (2015).

27. T.M. Yue, H. Xie, X. Lin, H.O. Yang, and G.H. Meng, J. Alloy. Compd. 587, 588 (2014).

28. W.-R. Wang, W.-L. Wang, and J.-W. Yeh, J. Alloy. Compd. 589,143 (2014).

29. H. Zhang, Y. Pan, Y.-Z. He, J.-L. Wu, T.M. Yue, and S. Guo, JOM 66, 2057 (2014).

30. N.A. Berjeza, S.P. Velikevitch, V.I. Mazhukin, I. Smurov, and G. Flamant, Appl. Surf. Sci. 86, 303 (1995).

31. V. Ocelík and J.T.M. De Hosson, Advances in Laser Materials Processing (Boca Raton, FL: Woodhead Publishing Limited, 2010), pp. 426-458.

32. Y. Shon, S.S. Joshi, S. Katakam, R. Shanker Rajamure, and N.B. Dahotre, Mater. Lett. 142, 122 (2015).

33. I. Hemmati, V. Ocelik, and J.T.M. De Hosson, Mater. Lett. 84, 69 (2012).

34. V. Ocelík, I. Furár, and J.T.M. De Hosson, Acta Mater. 58 , 6763 (2010). 